\title{
In search of the True Self
}

(in press Journal of Theoretical and Philosophical Psychology)

\section{Enrico Facco $^{1,2,3}$, Benedikt Emanuel Al Khafaji ${ }^{3}$ and Patrizio Tressoldi ${ }^{3}$}

${ }^{1}$ Studium Patavinum, University of Padua, Italy

${ }^{2}$ Inst. Franco Granone - Italian Center of Clinical \& Experimental Hypnosis, Turin, Italy

${ }^{3}$ Science of Consciousness Research Group - Dept. of Psychology, University of Padua

${ }^{4}$ Dept. of General Psychology, University of Padua, Italy

Correspondence:

Patrizio Tressoldi

Email: patrizio.tressoldi@unipd.it 


\begin{abstract}
The Self is an interdisciplinary topic encompassing neuroscience, psychology, philosophy and anthropology. Despite the wealth of data available on the topic, its definition remains elusive, while its meaning overlaps with terms such as consciousness, Ego and I, and so has created more confusion and redundancy rather than clarity. Its study is also endowed with deep epistemological and metaphysical implications, on which the accepted axioms, theories and the method of investigation closely depend.

Eastern philosophies have faced the problem of self-knowledge for some three millennia, achieving well-founded and valuable knowledge through introspection and meditation, and their results are worth being appraised in the Western, scientific study of the Self. We propose that the Self is related to the highest level of awareness in the continuum Ego-I-Self and, given its exclusively subjective nature (likewise consciousness), it can only be comprehensively explored through a neurophenomenological approach by merging the first and third person perspectives.
\end{abstract}

\title{
Keywords: Self; I; Consciousness; Ego; Philosophy; Materialism; Buddhism; Taoism; Yoga
}

\section{Public Significant Statements}

This article approaches the Self through a meta-philosophical perspective encompassing both psychology and Western and Eastern philosophies, with the aim of moving beyond the constraints of a single, limited paradigm and cultural perspective. A proper comprehension of the Self - which remains elusive, despite having been investigated for centuries - is essential for philosophy, psychology and neurosciences, as well as for everyday life in its personal, socio-cultural and political dimensions, being at the foundation of the Weltanschauung (the view of the world) - i.e., what we are, or believe to be, and the still unsolved problem of the mind-brain-body-outer world relationship. Missing the highest expressions of the Self (as done by the ruling materialist monist perspective of science and the Ego dictatorship of the today world) entails a scientific and cultural mutilation of human mind with devastating consequences for both the individual and the social life. 


\section{Introduction}

The concept of Self is vast, like all terms indicating subjective phenomena, including consciousness (Facco \& Fracas, 2018; Facco, Lucangeli, \& Tressoldi, 2017). Despite appearing familiar and being conceptually clear, its wide range of meanings make it ambiguous, calling for encompassing the whole spectrum of its meanings in the attempt to improve its comprehension and decrease possible misunderstandings. Furthermore, in the history of philosophy the meaning of the term Self greatly overlapped with ego, consciousness and soul, all concepts which, following Descartes, were provided with a different ontology with respect to the body. This engendered an increasingly dualistic stance leading to an ostensibly irreconcilable separation of what in vivo is an inseparable unity. The problem has both theoretical and clinical relevant implications. The former regards its definition, i.e., what Self is or is supposed to be; the latter includes the consequences of the adopted definition in in the management of psychological disorders.

The aim of this article is to provide an outline of main Self features with a transcultural approach, since the term Self has been widely used in psychology as well as in Western and Eastern philosophies. It is essential to avoid a limited ethnocentric perspective, with the implicit risk of inadvertently endorsing the claimed superiority of Western culture adopted in the past centuries from Enlightenment through the Victorian era, colonialism and the ideologies of the early 20th century. In fact, any ethnocentric perspective may inadvertently lead to what looks incompatible with the adopted metaphysics (i.e., the accepted theories and axioms) being a priori considered as irrelevant or false and, thus, well-founded ideas of other cultures being missed. A stance not buried yet.

The ambiguity of the term Self is also reflected by its meaning in different western languages: in English it mainly refers to self-consciousness and identity, while the German term Selbst also hints at an inner essence. Even more so, in the approach to non-western cultures the same terms may be used with different meanings, where formally opposite concepts may result to be compatible or even similar following a careful analysis (e.g., the concept of no-self in Buddhist tradition does not contradict the concept of Self, as discussed below).

The topic is so vast and tricky as to prevent the possibility of a rigorous analysis of all its elements within the limits of an article; the need for recognizing analogies and facing the above-mentioned ostensible contradictions may also give raise to misunderstandings and/or the impression of a shallow analysis. Nevertheless, it is of paramount importance to face it in the search of possibly relevant clues, helping to disclose some otherwise missed features of the Self. 
Given the complexity and degrees of approximation of the topic, the authors' aim is to raise doubts rather than claim certainties, i.e., to provide a few transcultural clues potentially useful in the definition of the Self, the relevance of which remains food for further reflection. In this context, some quotations of both eastern and western philosophers and fathers of modern psychology have been included to sketch a common field of reflection on possible transcultural compatibilities, rather than provide a rigorous, comprehensive exegesis of their thought.

The whole of meanings springing from this transcultural approach may also help better defining the relationship between Self, Ego and I. As a result, the hypothesis of a continuum Ego-I-Self is introduced at the end of the article, where each of them is considered as a functional pole or attractor of a single, whole, undivided human faculty emerging in the interaction with reality: a dynamic one in incessant transformation (including both growth and decline). Of course, it is only a provisional hypothesis to be submitted to further examination; if acceptable, it might help indicating the agenda for further reflection in the definition of these essential but still ill-defined components of the human mind.

Before outlining the concept of Self in Western and Eastern cultures, it is worth shortly describing the methods of a transcultural, metaphilosophical approach and the related metaphysical implications.

\section{About methods}

A transcultural approach calls for a metaphilosophical perspective, hopefully able to overcome cultural filters and constraints stemming from the adopted Weltanschauung (the worldview), which may lead one to perceive as irrelevant or even ostensibly contradictory what is not. Metaphilosophy - i.e., the philosophy of philosophy, or "the investigation of the nature of philosophy" (Lazerowitz, 1970) - is the part of philosophy devoted to the inquiry into the nature of philosophical questions and the methods (to be) adopted in answering them; in other words, it concerns the nature and possibility of knowledge and understanding (Overgaard, Glibert \& Burwood, 2013).

In this context, the metaphilosophical approach is aimed to the search for key concepts and meanings common to different philosophies, beyond their formal differences and different modes of theorization - i.e., to metaphorically seek for "roots rather than fruits" (Zajonc, 2004, Ch. 11) or walking down to the bottom of canyons, rather than building bridges on their peaks. This approach recalls the Philosophia Perennis advocated by Steuco in $16^{\text {th }}$ century and the dialogue dans la métahistoire by Henry Corbin (quoted by Izutzu, 1984), also taken up by Aldous Huxley (1946). The aim is not a simple matter of comparative philosophy based on a neutral, positivist approach as defined by Oursel in 1923; rather, it follows François Jullien's approach (2015), advocating a heterotopic 
common field of reflection, in order to get a better understanding of other cultures as well as reappraise the foundations of Western thought. According to Pasqualotto (2008), such an approach involves three interdependent factors - i.e., the subject who compares, the compared philosophical objects and the encounter between the two, leading to subject's transformation according to what has been found truthful. Here, the search of the roots implies a connection rather than separation of the different worlds, where the common field of reflection is aimed to find the problem's unity in the multiplicity of forms. It is a hard job, calling for a mix of neutrality, openness and capacity to properly understand and absorb concepts and ways of reasoning drawn from different cultures, in order to avoid the following of questionable stances:

a) Western ethnocentric dogmatism, stemming from an a priori assumption of the superiority of one's social identity;

b) Exoticism, i.e., the opposite of ethnocentrism;

c) The positivist approach to civilizations (emerged in a world marked by colonialism), claiming a detached, neutral comparative position aimed to treat all data from a third person perspective (3PP); the purpose of this approach is to classify intercultural differences, but it is unable to engender a valuable transformation of the subject.

In short, the proper approach should adopt the principle of equivalence of different cultures and place itself in-between them with openness toward the "other" and willingness to step outside one's own comfort zone (Burik, 2009, quoted by Weber, 2013). This approach allows getting new valuable knowledge from other cultures and making it a food for self-transformation. In general, this capacity of transformation is at the core of the development and transformation of the whole culture, society, Zeitgeist, Weltanschauung at all-times: in fact, the whole of philosophy and science would be meaningless, if taken apart from real life.

\section{Metaphysical implications}

The approach to the Self, with its subjective nature, is endowed with deep metaphysical (ontological) implications, the same involved in the debate on the foundation of the science of consciousness. Possible misunderstandings may also spring from an unyielding use of Aristotelian logic, a fact that calls for shortly reappraising its limits. ${ }^{1}$

The core of the actual debate on the foundation of the science of consciousness is the still unsolved problem of the mind/brain relationship, named by David Chalmers the "hard problem" (Chalmers,

\footnotetext{
${ }^{1}$ The huge problem of logic and truth-makers (Armstrong, 2012; MacBride, 2016), is far beyond the limits of this article, and will only be briefly sketched to provide a hint of its methodological relevance in this context [for further details, see Facco \& Fracas (2018); Facco et al. (2017)].
} 
1998, 2013), which may be considered as a long-term consequence of Descartes 'radical dualism i.e.,the ontologic split of res cogitans and res extensa (Damasio, 2003; Facco et al. 2017, Facco \& Fracas, 2018). Of course, the other Chalmer's problem, i.e., the "easy problem" (the understanding of brain circuitry underpinning consciousness) is far from being "easy" and its solution calls for hard work, but the method of study is available (the mechanist-reductionist approach is correct and powerful). Instead, the hard problem - i.e., the problem of subjective experience and qualia - cannot be properly understood by an objectivist approach skipping the first person perspective (1PP) ${ }^{2}$, a fact suggesting the need for a shift of paradigm.

In the ongoing debate on the foundation of the science of consciousness, materialist neuroscientists only consider the whole of subjective phenomena with their qualitative features in terms of brain circuitry, undermining the value of the 1PP. On the other hand, neuroscientists thinking that mind, qualia and experience cannot be simply equated to their neurocorrelates are labelled as dualists, (Pockett, 2014, Facco et al. 2017). Thus, even materialist monists keep a latent dualism, in that they accept the dualistic ontologic separation between brain and mind, while simply disregarding the latter a priori or equating it to its physical aspects (Bunge, 2007; Facco \& Fracas, 2018; Facco et al, 2017; Pockett, 2014; Ramsay, 2013, Severino, 2016). Instead, the study of subjective phenomena should merge the ruling 3PP and the 1PP in a whole. Despite 1PP and 3PP look logically incommensurable from an objectivistic point of view, both of them are needed for an appropriate comprehension: it is not a matter of reducing one another (as in reductive physicalism) but taking both of them into account, like two sides of the same coin. In fact, a scientific approach based on 3PP can detect and quantify objectifiable features of the Self, by relating them to behavior and brain mechanisms, but it is blind to the subjective dimension - i.e., the inner experience of oneself, identity, sameness, values and metacognition, which are at the core of conscious life, Self and their meaning. It may also disregard ethnic (non-scientific) components of psychological disorders, their related cultural factors and therapeutical implications (Watters, 2011).

An increasing dissatisfaction with the limits of this approach has developed in the past two decades and the need to reintroduce subjectivity in medicine has been increasingly advocated (Cardeña 2016; Facco 2014; Facco \& Fracas 2018; Facco et al 2017; Varela, 1996; Zeman 2000, 2006, 2009), while several scientific studies have already merged 1PP and 3PP in a whole [e.g., see Cardena, Jonsson, Terhune \& Marcusson-Clavertz, D. (2013); Ionta et al. (2011), Salomon et al (2013), Facco et al. (in

\footnotetext{
${ }^{2}$ The 1PP can be defined as the phenomenological, subjective mental contents, also defined as "qualia", the person is aware of and can communicate to others by language and behavior (Nida-Rümelin, 2015; Tressoldi, Facco \& Lucangeli, 2017; Tye, 2018).
} 
press)]. In short, skipping the 1PP leads to all subjective phenomena - including qualia and Self being lost, undermined or misunderstood; denying the value of subjectivity also looks to be selfcontradictory and self-destructive, since the whole culture - including science itself - is a product of the human mind with its irreducibly subjective nature, living in the world of consciousness.

\section{About logic.}

In Western thought a logical strategy of thinking has been introduced, in order to get a proper knowledge of reality and withdraw illusions. The Aristotle's logic - with its tripartite structure, made up of the principles of identity, non-contradiction and excluded middle (or Third) - has been the base of reasoning for over 2000 years, but the posterity turned Aristotle's philosophy into a sort of undisputed, dogmatic doctrine (Russel, 1959; Smith, 2018), a fact paralleled by the introduction of modern formal logic in order to overcome the limitations. Nevertheless, the latter still remains a specific competence of insiders, while the principles of Aristotle's logic are firmly entrenched in common sense; as a result, most people, including many scientists without specific expertise in logic, may unawares use and overestimate the traditional way of reasoning, with the implicit risk to draw questionable or wrong conclusions from the available data.

In the context of a metaphilosophical approach to the Self the Aristotle's logic or, better, its unyielding use, looks not enough, due to the following factors: a) ill-defined concepts make hard any clear-cut discrimination; b) transcultural commonalities may exist beyond their formal, ostensibly incompatible differences; c) different paradigms may call for different ways of reasoning.

Aristotle's logic dichotomously splits reality into two mutually exclusive categories (true/false) with the risk of inadvertent errors when judging uncertain facts, of which only a partial assessment is possible. Thus, paraconsistent logics, such as fuzzy logic and dialetheism, have been introduced in the $20^{\text {th }}$ century to deal with contradictions and probabilities in a more flexible way (Facco \& Fracas, 2018; Facco et al. 2017; Priest, 1990, 1998; Zadeh, 1965). The former admits a fuzzy set, where all possible values between 0 and 1 (i.e., false and true) are admitted. Dialetheism does not reject classical logic but admits that some (not all) propositions may be true contradictions, i.e., both they and their negations may be true (e.g., the above-mentioned Self and no-self concepts; see below). Therefore, it looks wiser and more prudent to consider dialetheism in the transcultural approach to the Self, in order to provisionally tolerate ostensible contradictions stemming from lacking knowledge, which may include the following components: a) metaphysical aspects, i.e., the (ill-) known properties of the observed phenomena; b) psychological and pragmatic factors (e.g., subject's the overestimation of beliefs and adopted axioms); c) syntactical factors (i.e., the formal aspect of 
contradictions). This process may also benefit from analogical reasoning, in order to improve the perception of similarities (Bartha, 2016).

Finally, the paradigm of other cultures may be based on different structures of reasoning; for example, Taoism, despite accepting logic and causality, is more focused on chance, coincidence and analogical knowledge, holding a non-dualist dynamic complementarity of opposites (Yin-Yang). For example, this is well established in the Law of Five Elements (五行, Wú Xing), still used in Traditional Chinese Medicine for diagnosis and therapy $\left(\right.$ Facco, 2014) ${ }^{3}$.

\section{Western psychology}

In psychology, the concept of Self was first introduced by William James (1890), including several aspects - i.e., the Self as the known and the knower, the material (including the sense of ownership), the social and the spiritual Selves (including the feelings of one's own subjectivity). A key concept of James' definition is the perception of self-identity - i.e., one's own personal identity, sameness an intriguing and still-puzzling phenomenon, making the concept of Self a sort of conundrum (see below). In fact, these features of the Self imply a sense of agency and continuity of identity over time, where social relationships, ideals, values, the inner/outer world relationship as well as mind and body are ever transforming throughout life from infancy through ageing and, finally, death.

James defined the spiritual Self as follows (James,1890, Ch. 10): "We may divide it [the spiritual Self] into faculties, as just instanced, isolating them one from another, and identifying ourselves with either in turn... But whether we take it abstractly or concretely, our considering the spiritual self at all is a reflective process, is the result of our abandoning the outward-looking point of view, and of our having become able to think of subjectivity as such, to think ourselves as thinkers... If the stream as a whole is identified with the Selffar more than any outward thing, a certain portion of the stream abstracted from the rest is so identified in an altogether peculiar degree, and is felt by all men as a sort of innermost centre within the circle, of sanctuary within the citadel, constituted by the subjective life as a whole. For this central part of the Self is felt. It may be all that Transcendentalists say it is, and all that Empiricists say it is into the bargain, but it is at any rate no mere ens rationis, cognized only in an intellectual way, and no mere summation of memories or mere sound of a word in our ears... It is something with which we also have direct sensible acquaintance, and which is as fully present at any moment of consciousness in which it is present, as in a whole lifetime of such moments".

\footnotetext{
${ }^{3}$ For an outstanding analysis of the role of chance in Taoism, see the Jung's forward to the I King (Wilhelm, 1950).
} 
Despite the James' starting point looks close to empiricist view, his pragmatist stance ${ }^{4}$ allowed him to face with great wisdom and open-mindedness also the most intriguing aspects of a kind of superior consciousness, knowledge and experience, related to enlightenment and what Aristotle called epopteía ${ }^{5}$. These are well described in the Varieties of Religious Experience as well as in his report of experiences following alcohol and psychotropic agents: "With me, as with every other person of whom I have heard, the keynote of the experience is the tremendously exciting sense of an intense metaphysical illumination. Truth lies open to the view in depth beneath depth of almost blinding evidence. The mind sees all logical relations of being with an apparent subtlety and instantaneity to which its normal consciousness offers no parallel... The ego and its objects, the meum and tuum, are one... and that truth was that every opposition, among whatsoever things, vanishes in a higher unity in which it is based; that all contradictions, so-called, are of a common kind; that unbroken continuity is of the essence of being". However, when the effects of nirous oxide faded away James reported what he named "the reverse of the medal" - i.e., an"instantaneous revulsion of mood from rapture to horror" interpreted as the inevitable outcome of the intoxication and marked by a pessimistic fatalism, feeling of impotence and indifference with the flavor of silliness and bewilderness. According to his view, the identification of contradictories - far from the Hegel's self-developing process - was a selfconsuming process, the outcome of which might be the feeling an "ultimate nothingness" or “meaningless infinity". Indeed, this may be the outcome of a passive, induced experience by a shortacting drug, which may help only transiently perceiving a superior state of consciousness, one is not ready to understand and properly manage following the return to the ordinary state of consciousness. This is the problem of all psychotropic drugs, which can only provide variable experiences (good or bad, ranging between the heaven and the hell) according to personality, dose, aims and context of administration: they are especially meaningless or harmful when their consumption resembles the opening of Pandora's box. On the other hand, psychotropic agents have accompanied both culture and spiritual development of the Homo Sapiens and have been used from prehistoric shamanic traditions until the native population of the present day. The plants, called plants of power, plants of

\footnotetext{
${ }^{4}$ James identified Peirce as the founder of pragmatism (then renamed as pragmaticism). The key concept of Peirce pragmatism is the practical bearing as a result for any statement to be considered meaningful. Also imagination is meaningful if it meets this criterion, and even the idea of God may be pragmatically "real" if it improves man's selfcontrolled conduct. James' pragmatism, holds a "sinechistic pluralism", compatible with both Peirce and Bergson (James, 1909), and moves far beyond the limits of an intellectualistic-materialist-determinist scientific approach; the latter is unable to provide appropriate responses to human questions, where beliefs, ethics and religion are concerned and involve their effects on individuals (Atkin, 2018).

${ }^{5}$ The term epopteía, derived from the mystery cults, is defined by Aristotle as follows: "The thought of the intelligible, pure and simple, goes through the soul flashing like a lightning, offering, sometimes only once, the opportunity to touch and contemplate... Who has really touched the pure truth of it thinks he owns, as in an initiation, the ultimate end of philosophy". (Aristotles. Eudemo, Fr. 10. In: Scarpi, 2012, p. 174-5)
} 
knowledge or plants of the gods, were used to manage people's problems (e.g., as pain killers or anesthetics allowing for surgery), help them adapt to stress and adversity and promote resilience. They were used in ancient Greece as well, e.g., within the rituals of Eleusis Mysteries (Facco, 2010, pp. 89-130; Facco \& Zanette, 2017; MacLean, Johnson \& Griffith, 2011; Nichols, 1999; Samorini 2000). In short, the way of enlightenment and Self-fulfillment cannot be a simple matter of psychotropic drugs administration: they are not necessary or may provide only helpful clues but even harmful bad trips, where what is essential is the mind path towards a full higher-order awareness.

This James' experience is in line with many other reports of a perceived superior state of consciousness - being transient experiences or steady conditions, with or without the use of psychotropic drugs - in the whole in the history of philosophy and religions, from Plato's myth of the cave to mystic experiences (Chen et al., 2011; Facco, Lucangeli \& Tressoldi, 2018; Forman, 1998; James, 1917) up to Adous Huxley report of the effects of mescaline (Huxley, 1954). All of them hint to a state of superior knowledge enabling one to grasp the (otherwise unattainable) truth, beyond the limits of the egocentric perspective of the ordinary consciousness affected by the mask of illusion (Māya according to Buddhism; see below). If this is the case, it suggests that this kind of reflective awareness may represent a higher form of awareness and metacognition, which, as such, may be assigned to the sphere of Self. Of course, its value must be properly recognized, checked and told from other similar but dysfunctional states belonging to delusional hypomania or mania, as already well established by Plato in the Phaedrus (265a): "[Socrates] And of madness there were two kinds; one produced by human infirmity, the other was a divine release of the soul from the yoke of custom and convention".

James' pragmatist stance led him to strongly criticize both philosophical and theological rationalism and spiritualism; he wisely warned against the mechanist-materialist proneness to a priori take nonordinary mental expressions as signs of dysfunction or pathology. In the context of a transcultural approach it is also worth mentioning that Nishida Kitarò, an outstanding Japanese philosopher of early $20^{\text {th }}$ century, came to the same criticism starting from the eastern culture perspective (Kitarò, 2014).

Freud only rarely mentioned the term Self and, even then, in a generic way, while Jung conceived the Self as the result of individuation and the enhancement of awareness springing from a well-balanced integration between the conscious and the unconscious. Individuation allowed to overcome the narrow limits of the egocentric perspective to include both the collective unconscious and spirituality, a process potentially enduring through the whole life. Later on, the concept of Self gained a wealth of further meanings, including both physiological and dysfunctional components. The former include, 
besides its phenomenal components, the concepts of self-expansion and creativity (Adler, 1912; Arieti, 1967), the sum of all its potentialities (Fromm, 1976) and its realization beyond the social mask (Maslow, 1954), while the latter - the other side of the coin - includes the possibility of false (Kohut, 1977), narcissistic (Kernberg, 1995) or isolated Selves (Bettelheim, 1972) (table 1). All of the reported features of the Self are valuable despite some ostensible contradiction, such as the concept of spiritual self and the behaviorist idea of a physically determined system of responses. Moreover, the concept of Self strongly overlaps with other features of the human mind - i.e., Ego, I, $\mathrm{Me}$, awareness and consciousness - all of which share their continuity with the unconscious functions at their base. As a result, the Self may range from a basic concept, almost interchangeable with the Ego, up to spirituality and soul (a concept beyond the aims of this analysis), the latter being closely related to philosophical and religious issues [see Crabbe (1999) as a review of the relationship Self/soul.

Tab. 1: Main features of the Self in psychology.

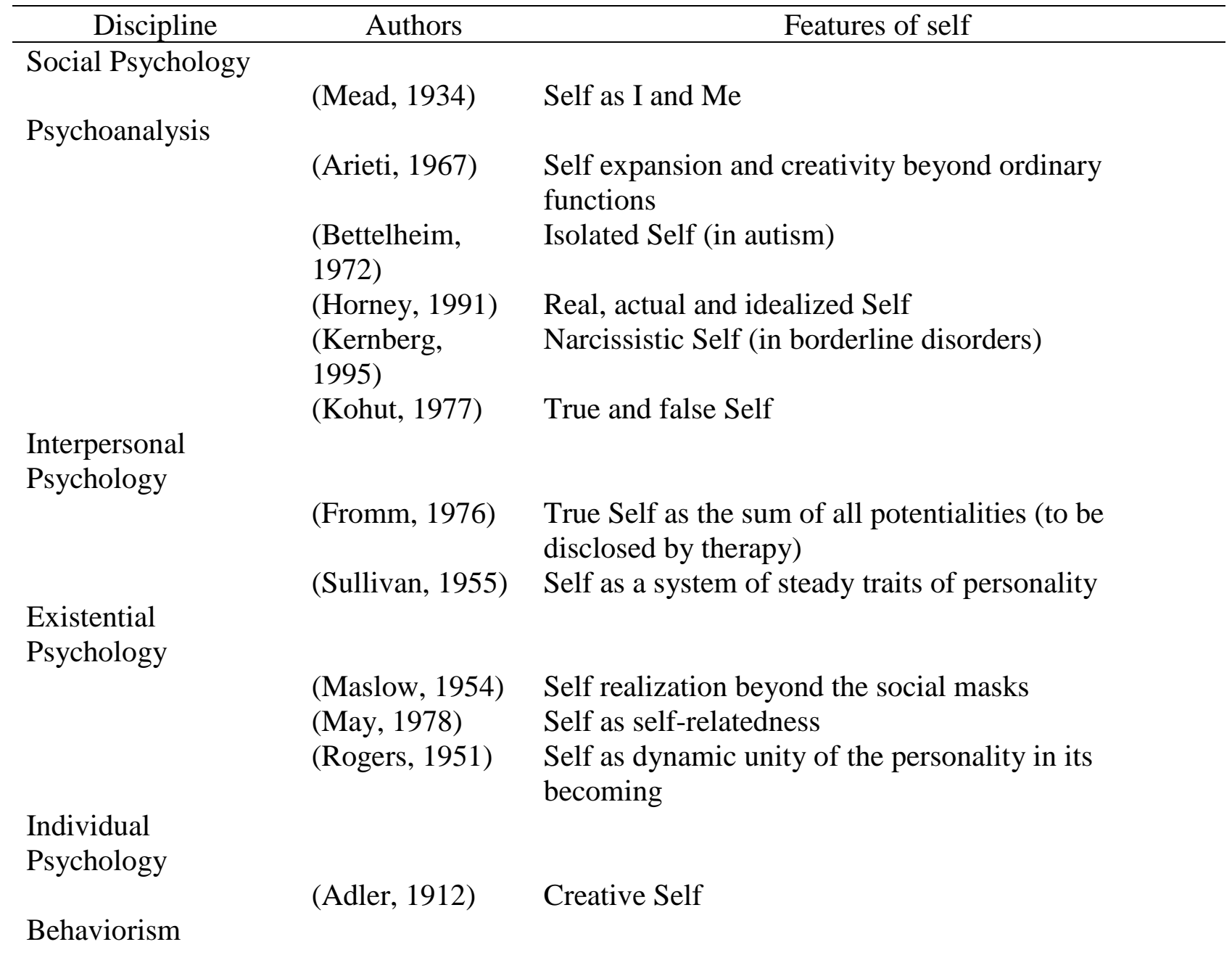


(Chambless \& Self as a functionally unified system of responses,

Goldstein, 1979) determined by antecedent factors.

Phenomenal Self, the subject is aware of.

\section{Cognitivism}

(Minsky, 1986) Self as self-image and self-ideal

The problem of comprehending the Self is of paramount importance in both neuroscience and everyday life because our way of being, what we are (or believe to be), the meaning of our life as well as its realization closely depend on it; this makes it an inescapably interdisciplinary problem, involving medicine, psychology, philosophy and anthropology. In fact, reductive definitions might lead to devastating consequences, such as a cultural and psychological mutilation when denying relevant functions of the human mind, such as the eliminative physicalist approach is inclined to do; on the other hand, some metaphysical assumptions of philosophy and religious denominations may skip the relevant physical and physiological aspects of mind functioning. Overall, this entails the risk of over- or underestimating human abilities, due to a priori metaphysical impositions by both dualist and materialist monist stances (for a critical analysis of their limits in the science of consciousness, see Facco \& Fracas, 2018; Facco et al., 2017).

\section{Philosophical issues}

As mentioned above, the Self has been contemplated for centuries in philosophy, where it hugely overlapped with the concepts of consciousness, Ego and I. The terms Ego and I also overlap with each other and have generally been used as interchangeable terms (for the sake of simplicity, in this section we shall use the term Ego only; thereafter, we shall briefly suggest their possible differences). The Ego has mainly been conceived as self-consciousness, which is also a distinctive feature of the Self. Self-consciousness has been defined as both the start point and the endpoint of the observation (Severino, 2016, p. 179 of the Italian version). On the other hand, being conscious - i.e., perceiving, recalling, acting, et cetera, - does not necessarily imply the existence of a unique level of awareness. In fact, awareness may extend up to metacognition and conscience - including the understanding of the meaning of one's emotions, reactions, thinking processes and objects of experience and actions, as well as what belongs to the field of dignity and values, overcoming the narrow limits of the ordinary egocentric perspective.

The modern concept of the Ego starts with Descartes, who, in Meditationes de Prima Philosophia (1641), equated it to the soul and considered it to be the foundation of human beings (cogito ergo 
sum). His radical ontological separation between the res cogitans and res extensa led him to state that the knowledge of one's mental state strongly differs from the knowledge of the outer world, including the knowledge of others' thoughts. Thus, he considered the perception of one's existence as intuitive, immediate, simple and self-evident, as well as the idea of infinite - then of God - which could not be inferred from the outer world. In German Idealism, Fichte considered the Ego and self-consciousness as the absolute, pre-logic foundation of consciousness, in which self-consciousness allows for introspection. Schelling introduced the idea of the development of the Ego from its primordial, unaware state up to the full realization of the theoretical and practical philosophies; unlike Descartes, he held that the thinking subject could not be fully transparent to itself.

From English Empiricism to physicalism, the transcendental, metaphysical components of Ego and self-consciousness were progressively abandoned in favor of phenomenal, functional ones and their relationship with physical, brain-related activities.

Locke considered the Ego as a feeling-intuition of one's existence, while, according to Hume, it was an a posteriori construct borne from memory, imagination and the dynamic collection of perceptions occurring in a rapid, unceasing flow. Afterwards, Nietzsche defined the Ego as an artefact without identity resulting from heterogeneous forces, Musil as a hole to be filled with matter drawn from the outer world and Lacan as the symptom par excellence of man - an epiphenomenon depending on the unconscious, not the foundation of man.

The problem of self-knowledge is a crucial one in the history of philosophy, given its ostensible difference with respect to the knowledge of the outer world held by Descartes. Empiricism refused the substantialization of the ego, but accepted the correspondence between the Ego and consciousness. According to Locke (Locke, 1689, II, 27, 9), "It is impossible for anyone to perceive, without perceiving that he perceives. When we see, hear, smell, taste, feel, meditate, or will anything, we know that we do so... And it is through this that everyone is to himself that which he calls 'self', not raising the question of whether the same self is continued in the same substance. Consciousness always accompanies thinking, and makes everyone to be what he calls 'self' and thereby distinguishes himself from all other thinking things; in this alone consists personal identity, i.e. the sameness of a rational being; and as far as this consciousness can be extended backwards to any past action or thought, so far reaches the identity of that person; it is the same self now that it was then; and this present self that now reflects on it is the one by which that action was performed". Hume moved farther and stated: "I may venture to affirm of the rest of mankind, that they are nothing but a bundle or collection of different perceptions, which succeed each other with an inconceivable rapidity, and are in a perpetual flux and movement" (Hume, 1739, I, 4, 6). 
Kant criticized the Hume's view of the simple bundle of collections holding that "no cognitions can occur in us, no connection and unity among them, without that unity of consciousness that precedes all data of the intuitions, and in relation to which all representation of objects is alone possible. This pure, original, unchanging consciousness I will now name transcendental apperception" (Kant, 1781, II, p. 232). The concepts of I, Self, and soul look partly overlapped in Kant's thought: "Soul consists of pure [lauter] synthesis and analysis of these representations. The I is noumenon; I as intelligence" (Kant, 1781, II, p. 338). In the Critique to Practical Reason, he emphasized the practical principles and their increasing values, from those established by individual will up to universal ethical laws i.e., the categorical imperatives, placed beyond the limits of the egocentric perspective and ordinary will (Kant, 1788). When mentioning Epicurus thought $(1,1)$, he stated: "Consistency is the highest obligation of a philosopher, and yet the most rarely found'. It seems us reasonable to speculate that the achievement of this consistency would be the expression of the full realization of the Self.

Kant considered consciousness as self-knowledge, an essentially rational, intellectual faculty able to evaluate itself, including its thoughts, behaviors and ethics, a concept far beyond the limits of perception and qualia and encompassing conscience. As a result, both Descartes and Kant held the view that consciousness, self-knowledge and soul could not be studied purely from an empirical, biological approach; instead, the knowledge of the soul could be directly achieved relying on both introspection and meditation on experience (Ferrari, 2010).

Despite the need for introspective self-knowledge, Kant ultimately rejected the idea that the only use of introspection - or apprehension through the inner sense - could achieve proper knowledge of the soul. Since the observation might alter the observed inner object, he viewed that one's actions also needed to be observed; in other words, the combined knowledge of the inner and outer worlds were required (Sturm \& Wunderlich, 2010).

\section{The problem of introspection.}

The core of the problem is the epistemic validity of introspection, which can be achieved only through 1PP. Nevertheless, the subject and the target of the observation are the same thing in this case, involving the risk of self-deception.

In general, the introspective perception of oneself has the authority of presumption of infallibility and truth; from a metaphysical point of view, it "is infallible if and only if one cannot have a false belief to the effect that one is in a certain mental state" (Gertler, 2017). The presumption of infallibility springs from the ostensibly direct correspondence between the perception and its object, which in turn depends on being unaware of the involved mind-brain unconscious coding processes. Thus, there 
is reasonable doubt that a short circuit may exist, where the observer may alter the observation. However, such an event in itself does not seem to be so different from the concern about the validity of perception of the outer world, reflecting the more general evidence of human fallibility in the process of knowledge as a whole. On the other hand, a proper use of introspection may lead to reasonable certainty about one's phenomenal states, given that they can be perceived only through direct experience and introspection, as shown in pain, one of the world's major health problems.

The example of pain. Pain is defined as a sensory and emotional experience and, being a matter of experience, is subjective in nature (IASP, 1979; Merskey, 1994, 2007). That is to say: no experience, no pain. Therefore, the subject can only perceive, check or communicate it through a 1PP; what the subject perceives and communicate are the only available data, and no one can gain better insight from a 3PP. The fact that a subjective experience like pain rationally looks non-epistemic makes it no less real and "true" (even "infallible") to the subject experiencing it. In fact, pain is a real clinical fact also for the doctors involved in its management from their 3PP, despite no one can objectively demonstrate and measure it. The problem is well synthetized by a famous sentence by Cameroun "Not everything that can be counted counts, and not everything that counts can be counted" (Cameroun, 1967, p. 13). It is worth emphasizing that these experiences are related to self-perception and self-awareness, rather than self-knowledge. However, they may move to the sphere of selfknowledge, when including other data, such as pain diagnosis and the subject's ability to analyze it and intentionally alter its perception up to the level of full analgesia trough introspective activity (e.g, meditation and hypnosis; see Facco, 2013, 2017; Zeidan et al. 2011).

The problem of the truth and truth-makers of a perceived inner state, such as pain, has been discussed in detail by Fumerton (2005). He questioned the idea that pain may be a genuinely mental state that cannot occur without one being conscious of it and shaped the problem using two mental experiments:

a) A subject being temporarily unaware of pain when distracted, claiming its possible persistence despite the subject being unaware of it;

b) A subject convinced that he is in pain without being aware of it, e.g., by a neurophysiologist scanning his brain and convincing him by his brain images that he is in pain.

Both examples are not tenable, since pain is an exclusive matter of subjective experience: in the first case, the pain simply stopped for a while thanks to distraction, while brain scans only show brain slices, not pain. Therefore, should the subject be convinced that they are in pain, the pain would start to exist as soon as the subject felt it by suggestion and vice versa, with no split between pain and the subject's awareness of it. The nocebo and placebo effects clearly show the intimate relationship 
between pain, its awareness and the role of experience and communication in its changes (Benedetti, Lanotte, Lopiano, \& Colloca, 2007; Colloca, 2014; Klinger \& Colloca, 2014; Kong et al., 2006). Furthermore, should Fumerton's mental experiments be endorsed, one should think that during general or regional anesthesia patients are in pain without being aware of it, denying the very concept of anesthesia.

Hypnosis and meditation allow for intentional, introspectively induced changes in subjective experience, perception, emotion and physical state, such as anxiety, pain perception and cardiovascular parameters (Casiglia et al., 2012; Facco, 2016; Facco et al., 2011; Facco, Zanette, \& Casiglia, 2014; Facco, Manani, \& Zanette, 2013; Facco, Pasquali, Zanette, \& Casiglia, 2013; Casiglia et al., in press; Orme-Johnson et al., 2006; Zeidan et 1. 2011). These effects are paralleled by significant changes in the activity of specific brain areas, showing the close, bidirectional mind-brain relationship and the shortage of the exclusive bottom-up hierarchy held by the materialist monist stance. This also calls for a short outline of neuropsychological aspects of Self.

Neuropsychological aspects of Self. In the neurophilosophical approach by Patricia Churchland, the Self is defined as an organized system of self-representations and meta-representations, allowing one to obtain coherent perceptions, projects and decisions emerging from neural models managing both internal and external inputs (Churchland, 2003). This definition avoids referring to the Self as a single, autonomous entity and emphasizes its multiple functions, while attempting to connect psychological and cerebral aspects (though in a rather generic form).

Self-consciousness includes self-detection, self-monitoring, self-recognition, Theory of Mind, selfknowledge and the ability to keep one's identity over time, relive the past and project oneself in the future in a sort of mental time-travel. Likewise pain, the inner self-awareness is essentially a private fact and lies beyond the boundaries of scientific scrutiny (Zeman, 2006); nevertheless, it is no less real than the other subjective features of consciousness linked to behavior. Damasio (1994) described three main brain subsystems at the base of Self:

1. The whole of the emotional and somatic representations of the body, including their states and their changes over time;

2. The autobiographical and dispositional representations (both declarative and prescriptive);

3. A subsystem allowing for the representation of oneself.

This neuropsychological structure implies the capacity of a continuous updating of the Self and its image through an iterative unconscious process able to manage the new data acquired over time, otherwise the representation of the Self would remain in a static and unchangeable representation. 
Furthermore, self-consciousness engenders one's capacity to observe oneself in an exocentric or allocentric way to obtain a sort of internal objectivity, an inner 3PP. This can be achieved when the following data are available; a) information on experience and the adopted responses; and b) the perception of oneself in the act of perceiving the object and reacting to it, allowing for a metarepresentation of oneself.

The above-mentioned factors allow for self-knowledge as well as an enlargement of the limited egocentric perspective of ordinary consciousness, reaching an object-object approach independent of the 1PP of the agent. The capacity of intentionally adopting a 1PP or 3PP seems to involve the use of different brain circuits, where the fronto-polar, somatosensory cortices, the right inferior parietal lobe and the default mode network look to be involved in the process of self/other distinction and mind wandering - including memory retrieval, planning, envisioning the future, and conceiving the perspectives of others (Buckner, Andrews-Hanna \& Schacter 2008; Damasio, 1994, 2003). This capacity is of paramount importance for cognition and metacognition, as well as in social relationships (dynamic and reciprocal in nature); it is learned throughout one's life, given the better capacity of adults to adopt a 3PP with respect to children (Dosch, Loenneker, Bucher, Martin, \& Klaver, 2010; Ruby \& Decety, 2004; Vogeley et al., 2004; Vogeley \& Fink, 2003). Furthermore, a deliberate and more detached 3PP may modulate both positive and negative emotional involvement and help to regulate it, a fact which does not occur in the unaware or spontaneous reactions of patients with psychopathology (Wallace-Hadrill \& Kamboj, 2016).

Thus, the possibility of overcoming the limited, ordinary egocentric perspective is admitted in both neuropsychology and philosophy, a fact that calls for reappraising the introspective activity on the way to the full Self enlargement and realization.

The concept of Self enlargement. Russell has well described the epistemic value of the enlargement of Self and the restructuring of inner/outer world relationship in an attractive way looking compatible with Eastern philosophies (Russel, 1912, Ch. XV): “All acquisition of knowledge is an enlargement of the Self... This enlargement of Self is not obtained when, taking the Self as it is, we try to show that the world is so similar to this Self that knowledge of it is possible without any admission of what seems alien... In contemplation, on the contrary, we start from the not-Self, and through its greatness the boundaries of Self are enlarged; through the infinity of the universe the mind which contemplates it achieves some share in infinity. For this reason, greatness of soul is not fostered by those philosophies which assimilate the universe to Man. Knowledge is a form of union of Self and notSelf; like all union, it is impaired by dominion, and therefore by any attempt to force the universe into 
conformity with what we find in ourselves. There is a widespread philosophical tendency towards the view which tells us that Man is the measure of all things... This view, if our previous discussions were correct, is untrue... What it calls knowledge is not a union with the not-Self, but a set of prejudices, habits, and desires, making an impenetrable veil between us and the world beyond. The man who has no tincture of philosophy goes through life imprisoned in the prejudices derived from common sense, from the habitual beliefs of his age or his nation, and from convictions which have grown up in his mind without the co-operation or consent of his deliberate reason".

Eastern meditation is a highly evolved introspective technique, practiced for some three millennia to liberate oneself from attachments and conditionings; therefore, both eastern philosophies and meditation cannot be skipped any longer in the process of definition of Self and the way of its full enlargement and realization.

\section{The Self in Eastern philosophies}

Eastern and Western philosophies can be considered as two great rivers with a common source, i.e., the prehistoric pan-Asiatic shamanism, which migrated to: a) central-south China, where Taoism was born; b) Shythia (and subsequently to India); and c) the Black Sea at Pontic Olbia, a colony of Miletus. From Miletus, shamanic traditions spread to the Ionic isles and Anatolia, where Pre-Socratic philosophers were born. Furthermore, huge commercial and cultural exchanges occurred between Greece, Persia, India and China even prior to the $6^{\text {th }}$ Century BC. Likewise, an unexpected link exists between Eastern meditation, hypnosis and incubation in the temples of Asclepius and Apollo in ancient Greece (Facco 2014, 2017).

From Aristotle onwards, the river of Western philosophy evolved through an increasingly logicanalytic, rationalistic and dualistic way, the edge of which is the Cartesian ontological separation of res cogitans and res extensa. As a result, Western culture increasingly focused on the outer world, disregarding the non-dualistic paradigm of Pre-Socratics and the wise warning $\gamma v \tilde{\omega} \theta \imath \sigma \varepsilon \alpha v \tau o ́ v$ (gnôthi seautón, know yourself) of the Apollo Temple in Delphi. Instead, Eastern philosophies mainly kept a non-dualistic stance and maintained a huge interest in the exploration of the inner world, considered in an inseparable continuity with the outer one.

Eastern philosophies are a complex, epistemically well-founded topic, the analysis of which is far beyond the limits of this article; here, we can only provide a few hopefully useful hints for a proper contemplation on the nature of Self and its enlargement, according to Russell's warning. 


\section{Indian philosophy}

The definition and nature of the human Self is one of the most relevant topics discussed in Indian philosophy - partly overlapping with the concept of ätman (soul) - which has given rise to different views. They range from the anatta doctrine (no-soul) in Theravāda Buddhism and the denial of a real Self to the idea of an unlimited, non-dual Self as the basis of absolute unity of all of reality. The different views also include the dualistic (Dvaita Vedānta) and non-dualistic (Advaita Vedānta) stances in the Veda tradition. Nevertheless, Dvaita Vedānta does not consider the two components of its dualism as independent or irreconcilable substances with different ontologies (like Cartesian dualism), but rather as complementary attributes of a unique reality. In other words, the ostensible contradiction between these monist and dualist stances can be dialetheistically solved in the BhedaAbheda doctrine (where bheda means division, separation and multiplicity, and abheda means unity and non-separation), i.e., the simultaneous difference-non-difference, the eternal continuity, imperishability and coherent nature of the Self. It is worth noting here the analogy with Taoism and its Yin-Yang polarity (see below), the concept of Being by Parmenides ${ }^{6}$ as well as the convergence of opposites by Heraclitus.

Yoga. The whole Indian culture is imbued with Yoga, the etymology of which stems from the Sanskrit term yujir (binding together, joining). It indicates the reunion of mind-body, I-non-I (i.e., mind-body-world) and individual ātman-universal Ätman (Eliade, 1994). As a matter of fact, it can be considered as a combination of binding-unbinding, involving the following three components:

a) re-joining mind and body in their inseparable psychosomatic unity;

b) unbinding the mind from all its conditionings, illusions and veils (i.e., $M \bar{a} y \bar{a}$, the mask of the illusion of ordinary consciousness);

c) Samāadhi, the endpoint of yoga meditation, where the separation between the knower, knowledge and the known is overcome and the fusion ätman-Ätman (individual-universal Selves) is reached. Atman is also sat-cit-anānda (being-consciousness-bliss), which is eternal, beyond space and time (Eliade, 1994).

The first mention of the Self in Indian texts is in the Upanisad, the texts of the Veda tradition (Veda in Sanskrit means knowledge) composed between the $2^{\text {nd }}$ millennium and $7^{\text {th }}$ century BC. The Kena Upanișad poses the problem of Self as follows (I, 1): "Who senses the mind to wander afar? Who

\footnotetext{
${ }^{6}$ As Parmenides stated in the Perì Phýseos "From this point mortal opinions learn, listening to the deceitful ordering (kosmon) of my words,...for to name shapes they (mortals) established two knowings of one which it is not right; in this they have wandered stray, and they distinguished things opposite in body and established signs apart from each other".(Fr. 8. 50-55).
} 
first drives life to start on its journey? Who impels us to utter these words? Who is the Spirit behind the eye and the ear?" The Māṇ̂ukya Upaniṣad $(\mathrm{I}, 12)$ contemplates the fusion ätman-Ätman, a state reachable during turiya, the fourth state of consciousness (beyond the ordinary state of consciousness, sleep and dream). The Kathopanișad (II,6) also recognizes yoga meditation as an effective way to master Self-control and liberation from all attachments, suffering and conditioning, i.e., a highly evolved tool for metacognition, wisdom and enlightenment.

The Patañjali’s Yoga-sütra contemplates the Self and its full realization through meditation as follows (Bryant, 2009; Swami Veda Bharati, 2009):

- Samādhi-Pāda (Ch. 1): "Yoga is the control (nirodha) of the modifications of the mind field (2)... Then the Seer abides in Itself, resting in its own True Nature, which is called Selfrealization (3)... Indifference to the subtlest elements, constituent principles, or qualities themselves (gunas), achieved through a knowledge of the nature of pure consciousness (purușa), is called supreme non-attachment (paravairagya) (16)... Through this practice the immutable Self is revealed and all obstacles are removed" (29).

- Sädhana-Pāda (Ch. 2): "The uniting of the seer (the subject, or experiencer) with the seen (the object, or that which is experienced) is the cause or connection to be avoided (17)... The Seer is but the force of seeing itself, appearing to see or experience that which is presented as a cognitive principle” (20).

- Vibhüti-Pāda (Ch. 3): "But we learn nothing from the true nature of another person, for they are not an object that can be perceived (20)... By practicing samyama [meditation] on the heart, knowledge of the mind is attained" (35)... From that discriminative knowledge comes awareness of the difference or distinction between two similar objects, which are not normally distinguishable by category, characteristics, or position in space” (54).

Buddhism. Buddhism moves farther in the definition of consciousness, suffering and Self. It started in the $6^{\text {th }}$ century BC following Siddharta Gautama's observation of the omnipresence of suffering and his intention to liberate both himself and the whole of humanity from it. The origin of suffering was identified in the five $s k a n d h a^{7}$, the aggregates of ordinary consciousness.

On social point of view, Buddhism represents a radical reaction in favor of the universal human rights against the division of Indian society in impermeable classes held by Brahmanism. Despite not rejecting the idea of $\operatorname{God}(\mathrm{s})$, it disregards it, being a matter of a "noble silence". In fact, it is not

\footnotetext{
7 The five skandha are: 1), the matter and form of objects and their related sensory faculties; 2), perception, feelings and passions; 3), predispositions, memory; 4), volition; 5), consciousness, including the other four skandha.
} 
investigable and cannot be solved with concepts, such as the western one of causa sui; thus it relies on a secular, rational search of true and proper way of being, living and dying on the way of liberation and enlightenment (bodhi). This calls for moving beyond $M \bar{a} y \bar{a}$, the mask of illusion of the ordinary consciousness. Thus, Buddhism must be regarded as a profound, epistemically well-founded secular philosophy-psychology exploring the mind-body-world relationship. In western culture this is a never-ending, century-old philosophical dilemma, dualistically marked by the opposition between science and Church, materialism and immaterialism, realism and idealism: perhaps, it calls for a new way of reasoning able to overcome their ostensibly irreconcilable opposition [see Facco \& Fracas (2018), Facco et al. (2017) for further analysis].

The key points of Buddhism are the concepts of impermanence (anitya in Sanskrit, anicca in Pali), reality as vacuity (śünyatā), total interdependency of all entities (where no one is endowed with an autonomous and intrinsic existence) and, thus, the inexistence of an Ego and Self (the edge of which is the Zen doctrine of no-mind). The concepts of no-mind and non-existence of an Ego and Self are linguistically tricky: the former does not mean a sort of dementia, while the latter indicates they are non-existent as independent reified "things" but, rather, as conventional, functional aggregates submitted to impermanence (anicca). The concept of impermanence is well painted by Heraclitus as well: "No man ever steps in the same river twice, for it's not the same river and he's not the same man" (fragment DK 49A).

The Buddhist concept of no-self does not exclude the Self, a key point to avoid misleading conclusions. Indeed, the Ch. 12 of Dhammapada is devoted to the Self: "One truly is the protector of oneself; who else could the protector be? With oneself fully controlled, one gains a mastery that is hard to gain" (160). Thus, the Self should be told from the ordinary consciousness with its attachments, conditioning and unaware proneness to take mental objects (including the very idea of the Ego and Self) for the mind. This is also in line with the concept of nirodha in the Patañjali's Yogasūtra (Samādhi-Pāda, 2,3), which means the cessation of the obscured phenomena of the ordinary consciousness yielded by discernment and the ability to recognize the pure consciousness. In other words, nirodha is the empty, lucid, unflappable dynamic mind beyond any perception, concept and mental object, the pure awareness of the agent, the witness hosting mental objects (Cornu, 2001; Facco, 2014, Ch. 2).

In Mahāyāna Buddhism, the way of liberation is defined by the Wheel of Dharma (Tridharmacakra) ${ }^{8}$ and the Noble Eightfold Path (right view, right resolve, right speech, right conduct, right livelihood,

\footnotetext{
${ }^{8}$ The Tridharmacakra includes the Four Noble Truths, the Sütra of the Perfection of Wisdom (Prajñāpāramitā), the teaching of the consciousness base-of-everything (älayavijñanna) and the Nature of Buddha (tathägathagarbha)]
} 
right effort, right mindfulness, and right samadhi). In short, the no-self should be regarded as the condition of enlightenment achieved through the Self; in this process, smriti (mental presence) is essential to reach the extinction of individuality, i.e. nirvāṇa (Pali: nibbaba).

The doctrine of impermanence wisely considers empirical reality as a never-ending, ever-fluctuating field of activity in perpetual motion and change; this is a surprisingly modern view, akin to Heraclitus and compatible quantum physics. According to quantum physics, the world is not composed of solid objects and matter conceived in classical terms; rather, it is made of vacuum-energy-information and interrelated events, where matter emerges from the vacuum as a concentration of energy, and, as such, is a secondary product (Wilczek, 2010). If this is the case, a materialist view based on the classical concept of matter, conceived as the primary manifestation of the physical world, is obsolete and surprisingly outdone by the thousand-year old concepts of anicca and śūnyatā (Facco, 2014; Facco \& Fracas, 2018; Facco et al, 2017). Sünyatā refers to reality in itself and indicates what remains once the modalities of perception, qualia, mental objects, images and categories are filtered out. This concept is epistemologically well-founded and surprisingly modern, akin to Kant's critical dualism and the natural illusion he warned against (i.e., the ingenuous, phenomenal realism taking concepts and images for the phenomena in themselves).

The Indian concept of consciousness is neither ontologized nor substantialized, as indicated by the Sanskrit terms vrtti and cittavrtti (wave, vortex of the mental activity), which define it as a dynamic, funtional attractor, not as a reified entity; the Ego is also conceived as a functional, conventional aggregate, void of intrinsic autonomous existence. On the other hand, àlayavijñana (the consciousness-base-of everything, the primordial base of consciousness or consciousness-depository) is unconscious and holds the view that imprinting extends to previous reincarnations, implying some form of continuity and, thus, the possibility of karma. Thus, the liberation from suffering paradoxically consists of the fulfilment that there is no one in need of liberation.

Suffering pertains to the ordinary consciousness and Ego, while death, the cause of their annihilation, is their tragedy. Once the dictatorship of the Ego and its limited, illusory perspective is extinguished, one can move beyond, towards bodhicitta (awakening, wisdom, enlightenment). Bodhicitta, in Western terms, may be considered as the highest form of enlargement of Self, where the egocentric perspective is withdrawn and one is no longer separated from the non-Ego, becoming a microcosm of the entire world. This is the common trait of all the sages and the great, enlightened men of all cultures and times, including mystics (Facco et al., 2018).

If the above discussion is correct, one can provide some cues to properly face the no-mind doctrine, a concept largely incomprehensible for the Western reader. It is a keystone of Zen Buddhism, 
indicating the need to move beyond the limits of conceptual thought, a process akin to Jung's individuation, but able to reach far deeper, transcendental levels with respect to those of the collective unconscious. According to Zen, Freud's psychanalytic unconscious, being part of the empirical mind that interacts with the outer world, still belongs to the superficial consciousness (Suzuki, 1958), while Jung's collective unconscious, though non egoic and much deeper, still lays within archetypes, images and, thus, the world of concepts and mental categories. Instead, the aim of no-mind is to reach the buddhadhätu (suchness, original nature, Buddha-nature, the original nature latent in every living creature) common to all sentient beings. It lays beyond any human mental category, thought, apparent multiplicity or separation hailing from the illusory contact of the Ego with the outer world. The nomind is in line with both the concept of nirodha in Patañjali's Yoga-sūtra and the fulfillment of the Cosmic Ego following kashf (unveiling) in Sufi tradition (Facco, 2014; Izutsu, 1984; Patanjali YogaSutra., 2009): it might be conceived as the liberation from the narrow limits of the Ego and attainment of the full expression of Self. Here, one realizes to be an undivided part of the world, where the conventional meanings of time and space dissolve, as well as any anthropocentric, illusory conceptualization, substantialization and ontologization. It may paradoxically result to be the best attempt to reach the highest form of 3PP, able to comprehend the reality beyond human cultural categories (i.e., the reality of the Reality) and, perhaps, is the only opportunity to overcome Kant's natural illusion.

\section{Taoism}

Taoism stems from the hermits called yin by Confucius in a country strongly imbued with shamanic tradition; it subsequently evolved in a mature discipline encompassing the profound philosophical thoughts of Lăoẓ̌ and Zhuāngẓ̌, as well as Traditional Chinese Medicine. Lăož̆ defined the Tao (Dào in pinyin transliteration) and its immutable laws as the basis of the ever-changing phenomena of life and the universe.

In the Tao Te Ching (Dàodéjīng, in pīnyīn) Lăož̆ defines the Tao as the unnamable, of which Yin and Yang are opposite, complementary attributes, that only exist in their reciprocal, dynamic relationship: “The way that can be charted isn't the constant Way; The name that can be named isn't the constant name. It is nameless and Heaven and Earth's beginning, It is widely known as the ten-thousandthings' mother... The mystery of the Mysterious is the gateway of all subtleness... The ten-thousandthings under Heaven arise from what is, What is arises from what isn't' (Lao Tzu, 2009, 1).

There is a surprising similarity between the concept of Dào and the original meaning of Parmenides' Being in their relationship with the phenomenal reality, a meaning which has been lost following 
Parmenides" "parricide" by Plato and Aristotle (as deeply discussed by Severino, 2016). It is worth mentioning that the term "being" in its original meaning does not have a proper translation into Chinese - where 存在 (cúnzài) means existence and 生物 (shēngwù) creature - making it difficult to translate Parmenides' thoughts; perhaps the best correspondence is the term Dào. In fact, Parmenides' "being" is the eternal, timeless and steady background of the emergence of the partial, ever-changing phenomenal appearance (i.e., existence), which has been later on taken for "being".

As far as the personal virtues and Self are concerned, Lăož̆ affirms (Lao Tzu, 2009) : "Those who know people have wisdom, One who knows himself has clarity. Those who are victorious over others are powerful, One who is victorious over himself is strong" (33)... Therefore sage men are self-aware and not self-absorbed, Self-respect is not self-importance" (72). And Zhuāngzĭ (2009) says: “The perfect man has no self; The spiritual man has no merit; The holy man has no fame (Ch. 1)... Do not let your outward stance affect your inner self, nor allow your inner self to be drawn out (Ch. 4)... One who seeks for fame and thereby loses his real self is no gentleman (Ch. 6)... The mean or petty person has been willing to risk his very body for gain. The scholar risks his own selffor fame... All of these different types, with differing claims to fame, have all damaged their innate nature and risked their lives in the same way (ch. 8)... To describe him, you talk about his unity with the great All. The great All has no self. Having no self, he does not see himself having belongings! (Ch. 11)... His knowledge is firmly rooted in the origin of self, and encompasses even the spirits. His Virtue embraces widely. His heart goes out to what is beyond him ... Beware, for he would rely upon others rather than on Heaven, caring for his own self first and having little regard to the lives of others... Everyone in the world seemed only concerned with his own self. This meant the whole world was full of anxiety (Ch. 14)... If you were to be serious in your cultivation of your own self, careful to guard the truth and willing to allow others to be as they are, then you could have avoided such problems. (Ch. 31)... One who does not exist in self sees others as they really are" (Ch. 33). The above quotations show the no-Self as the condition of the sage, where no-Self (like the no-mind in Zen Buddhism) means liberation from the narrow, illusory egocentric perspective of ordinary consciousness in the process of enlargement of the Self. The way of Tao looks paradoxical and is hardly understandable to the ordinary man, nonetheless is the right way, as emphasized by Lăož̆: "The poor scholar hears the Way and loudly laughs at it. Not to have laughed at what he heard still falls short of believing it is the Way" (Lao Tzu, 2009, 41).

To summarize, an essential aspect of both Taoism and Indian philosophies is the awareness of the illusion of an Ego as an independent substance split from the rest of the world. Tao is the Unconditioned Absolute, the background of the multiplicity manifested in the phenomenal world 
(Izutsu, 1984). Here, the no-Self can be at least partly equated to the Zen no-mind, the Sufi's Cosmic Ego and Jung's individuation. Finally, the need for liberation from the Ego is a universal, transcultural philosophical achievement of both Eastern philosophies and mystic currents of Abrahamic tradition, from Desert's Fathers (e.g., Evagrius Ponticus) to Meister Eckhart in the Christian mystic currents, to Sufism in Islamic and Kabbalah in Hebrew traditions. Despite looking odd to the egolatric Western spirit of the time, they are epistemically well-founded and compatible with some aspects of the philosophy of Self, especially the Russel's one: thus, they are worth being carefully appraised in the process of its comprehension.

\section{The continuum Ego-I-Self}

“The Self! Who is it!" one could say paraphrasing don Abbondio in Manzoni’s Promessi Sposi, when thinking to himself about Carneades (the skeptical $2^{\text {nd }}$ century BC philosopher doubting the ability of both sense and reason to achieve truth). This looks to be the case of the definition of the Self as well, given the uncertainties permeating both psychology and philosophy, including their metaphysical and epistemological implications, the broadness of concepts and the ambiguity of language. There is nothing inherently inferior with these uncertainties, but it is worth trying to better define them for the sake of clarity in the hope of improving their knowledge and communication.

As already mentioned, the terms Ego and I have largely been used interchangeably, but their meaning may reflect different aspects in the Ego-I continuum; likewise, using the term Self and simply equating it to the Ego or the I seems to be questionable, since a single term would be enough in this case. Therefore, we shall try to shortly sketch some potentially helpful clues in the process of defining them.

According to psychanalysis and social psychology, the I develops during the first years of life and, thus, it reflects the social, culturally sensitive process of the maturation of the Ego; the same is for the Self, a process potentially enduring the whole life. Since all terms, including the prefix $e g o$, entail negative meanings (e.g., egocentrism, egoism, egopathy, egodystonia and egotism) it seems reasonable to consider the Ego as the primary part of the Ego-I continuum. If this is the case, the Ego is akin to Narcissus seeing his own reflection in the water, falling in love with it and disdaining those who loved him. The Ego is also akin to Hobbes' cupiditas naturalis (natural lust) as well, a concept well painted as the Lord of the World in the Gospel of Luke $(4,6)$ - where the devil resembles an outer projection of the inner features of the Ego - and as Māra the tempter, its analogous in Buddhist tradition. The I, which develops in the first years of age, may be considered as a more mature principle 
of reality stemming from the more callow Ego. The $\mathrm{I}$ is able to conceive the rights of others and even altruism; the Ego is not.

The variety of Self-related terms and the overlapping of their meanings with consciousness, Ego and I has created more confusion and redundancy than clarity due to the difficulty of grasping its nature, as emphasized by Kohut (1977, pp. 310-12): “The self... is, like all reality .... not knowable in its essence... We can describe the various cohesive forms in which it appears, can demonstrate the several constituents that make up the self, and can explain their genesis and functions. We can do all that, but we still will not know the essence of the self as different from its manifestations".

In the past decades, the reflections on the nature, origin and features of the Self have been assigned to the following main categories: biologic, interpersonal, cognitive and spiritual. According to Morin (2017), a classification of the Self terms may include the following items: 1) Basic terms related to self-perception (e.g., self-awareness); 2) Non self-terms related to other self-terms (e.g., Theory of Mind); 3) Processes related to the executive self (e.g., agency, volition and self-control); 4) Selfviews, including contents and feelings about the self (e.g., self-esteem); 5) self-bias and selfdeception; 6) Reactions to the Self (e.g., self-compassion or blame); 7) Interpersonal style (e.g., selfconfidence). Some features of the Self may belong to more than one category, while metacognitive ones, such as mindfulness and self-awareness, may extend to the spiritual Self in its broader sense; however, the ruling materialist stance of the scientific approach is inclined to lessen or refuse it, especially when involving an ostensibly dualist, transcendent or mystic flavor. Nevertheless, these components might result to be more relevant than commonly thought and compatible with science, once century-old cultural filters and prejudices are recognized. Here, we shall focus on these spiritual, metacognitive features of the Self for three main reasons:

1. The other features have already been well classified and discussed elsewhere;

2. The materialist monism is self-contradictory on metaphysical point of view (Severino, 2016);

3. The spiritual Self, despite disregarded by materialism, remains of crucial importance in the comprehension of both human mind and reality, a topic endowed with deep epistemological implications;

4. Denying it might lead to relevant human mental faculties being lost.

When one refrains from substantializing and reifying the Ego, I and Self, they may be conceived as a continuum - i.e., a single, functional attractor - where each of them reflects different stages of development embedded in the inseparable mind-brain-body-world unit. According to this hypothesis, the Self would be the most mature, wise, non-egoic expression of the human mind - potentially 
extending up to the extreme limits of the Sufist cosmic ego and Zen doctrine of no-mind - while the Ego would be the primary one (as schematically represented in Fig. 1).

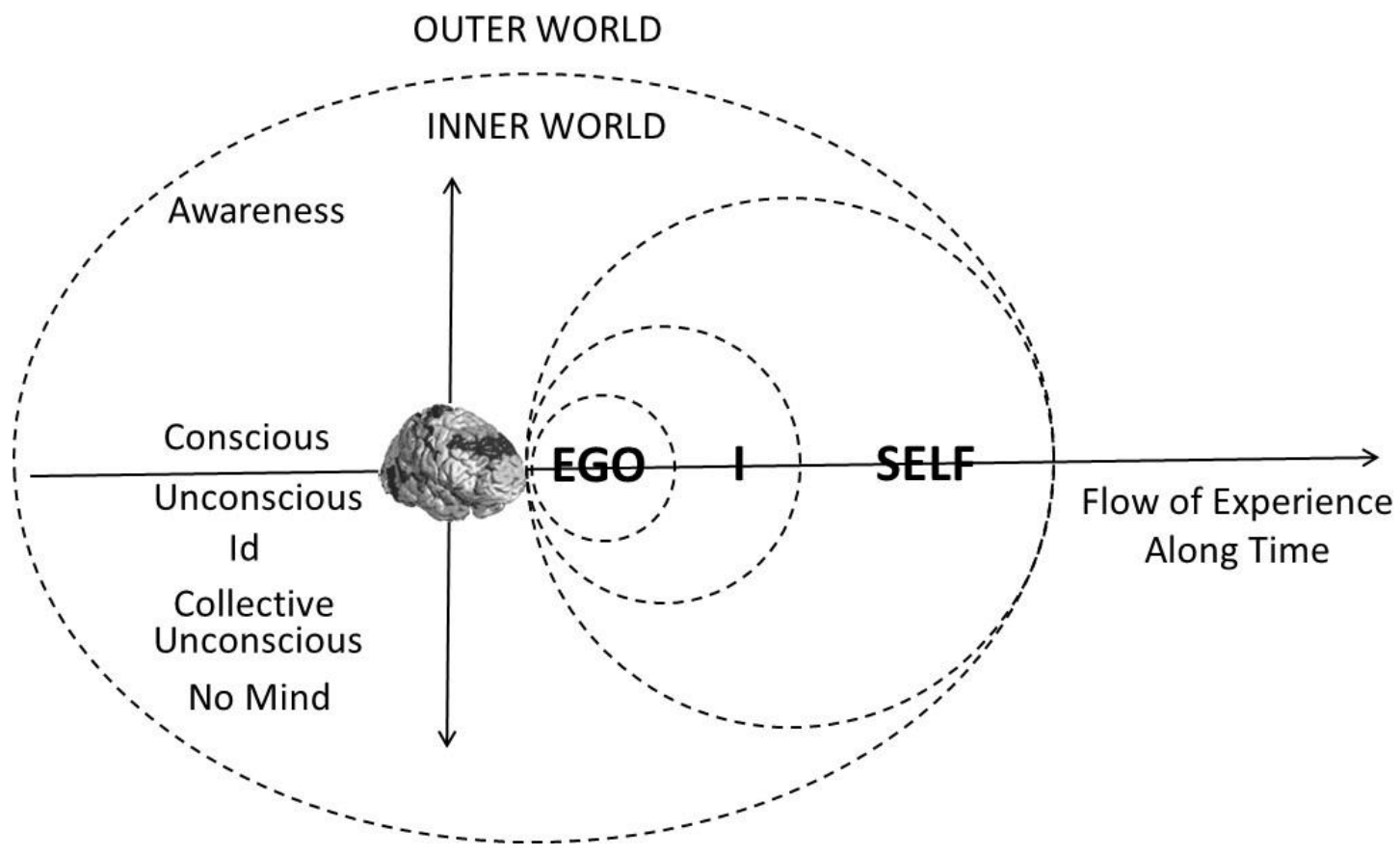

Fig. 1: The development of the Ego-I-Self as a continuum, encompassing the unconscious up to the deepest levels of no-mind held by Zen Buddhism.

The reason for hypothesizing a continuum, is that the both I and Self are the result of at the process of development from the first, primary appearance of perception of oneself in infancy. If this is acceptable, Ego, I and Self might be considered as different stages of development of the sense of agency and identity stemming from the contact and relationship with the outer world. Here, the I may be considered as a broader attractor than the Ego, including and partly able to control it. The Self may then be conceived as the broadest one, encompassing and able to control both of them, endowed with the full development of Buddhist smriti and allowing to become the Taoist strong man "victorious over himself'. Its full development may allow for an integration of unconscious activity - Jung's process of individuation - up to the level of wisdom, sageness, spirituality and enlightenment.

Kant (1784) defined enlightenment from his rationalistic perspective as a matter of conscience and freedom - i.e., the man's emergence from his self-imposed nonage, become a sort of second nature to him and constrained by dogmas, formulas and their abuse dictated by the guardians of the cattle. This definition is in line with the above-discussed concept of Self as well as Kant's moral laws, graded as hypothetical and categorical imperatives with their different levels of validity (Kant, 1788). The 
former might be assigned to the Ego or I and the latter, the universal ones, to the Self. The conflict between circumstantial, partial rules and universal laws has been well painted and is eternally reviving in the Sophocles' Antigone - i.e. the Creon's decree of not burying Polyeices (brother of Antigone), and Antigone's decision of doing it in spite of the ban:

"[Antigone] Yea, for these laws were not ordained of Zeus,

And she who sits enthroned with gods below,

Justice, enacted not these human laws.

Nor did I deem that thou, a mortal man,

Could'st by a breath annul and override

The immutable unwritten laws of Heaven.

They were not born today nor yesterday;

They die not; and none knoweth whence they sprang" (450-7).

One can speculate that the universal, unwritten laws of Heaven pertain to the sphere of Self, while Creon's one, stemming from his hubris, are ruled by the Ego, according to Teiresias' warning:

\footnotetext{
"Men who put their stubbornness on show

invite accusations of stupidity.

Make concessions to the dead-don't ever stab

a man who's just been killed. What's the glory

in killing a dead person one more time? "(1144-8)
}

Interestingly, the doom of Creon and his family, predicted by Teiresias, recalls the Greek concept of Ananke (the Necessity) as well as the Indian concept of karma, to be meant as the ultimate, implicit consequences - thus the related responsibility - of one's wrong behaviors.

The features of Self identified by the reductionist approach remain valuable; what is questionable is the claim of exclusivity of the reductive physicalist metaphysics, risking to deny the best, higherorder functions of the Self and, thus, leading to invaluable gifts of human mind being culturally lost. Indeed, the capacity for mutual understanding among humans of different races and cultures depends on common universal features, be it Jung's collective unconscious and/or the Self (including the noself and no-mind concepts of Zen Buddhism). Perhaps the Zen no-mind, in addition to the Taoist noself, might extend even further, up to being in touch with any non-human sentient beings. This theme is dear to hagiography, which has symbolically represented this universal, cosmic ego as the capacity to speak to animals, like the story of St. Francis and the wolf in Fioretti di San Francesco. Leaving 
out its theological aspects, the story might also be considered as a sort of psychotherapy of the wolf (which is the same as the egocentric man with its natural lust). Such a reconciliation between animals, nature and man in an unseparated, balanced whole is a huge and impeding problem of today, given the threat of worldwide ecologic disaster, where man seems to have taken the place of the St. Francis' wolf.

To summarize, the whole of ego, I and Self are embedded in culture and take shape in the flow of experience over time. In this continuum, the Self may expand from the basic sense of personal identity up to the level of non-egoic collective/spiritual dimensions. The former has been described as Me by James, the Ego by Freud, the Epistemological Self by Klein and the Five-Kinds of Self-knowledge by Neisser. The latter is compatible with James' Spiritual Self (granted his above-mentioned reflections), Klein's Ontological Self, Jung's individuation, and the Self by Assagioli (1988).

According to Klein, the Self is a multiplicity of aspects consisting of both neural-cognitive instantiations and first-person subjectivity, the former being material in nature and objectifiable (thus amenable to scientific scrutiny) and the latter, the Ontological Self, being immaterially subjective (as such hardly grasped by the materialist dogma of modern science). Klein correctly emphasizes the metaphysical, axiomatic nature of scientific materialism and its lack of a superior claim holding both material and immaterial aspects of the Self; the latter includes its implicit persistence even in severe neuropsychological disorders, in which the sense of personal ownership (which contingently joins both the Epistemological and Ontologic Selves to each other) is lost.

Assagioli (1988) - in his posthumous writings entitled Transpersonal Development - considered the Self as belonging to the higher aspects of unconsciousness, not for a demonstration but for being aware of it as an experienced fact of consciousness: "There comes a point at which the superconscious becomes conscious, remains so for some period of time, and then returns to the superconscious state. I would point out here that the 'superconscious', 'unconscious' and 'conscious' are adjectives, that is to say they are temporary conditions of a psychological fact" (p. 20). This may spontaneously occur as enlightenment, inspiration, Aristotle's epopteía, or following an inner search leading to the sphere of consciousness being enlarged, e.g., through meditation. Unlike superconscious events, the Self looks stable and unchanging, providing a sense of identity throughout all physical and psychological changes, as recognized by Assagioli (1988, p. 26): "But even to say 'I no longer recognize myself" implies, paradoxically, an obscure, hidden sense of underlying continuity. Otherwise, there could not even be a sense of not recognizing oneself'. Anyway, identity looks a still ill-defined, mysterious feature of human mind. 


\section{On the conundrum of identity}

Identity looks odd, if not mysterious, despite the aforementioned Damasio's analysis providing a relevant insight into its basic neuropsychological mechanisms. In fact, they cannot provide a full explanation for the sense of identity, one's own singularity, personality and metacognitive capacities, which remain part of the "subjective" self as it is experienced. It is worth reaffirming here that reductionism is a valid and powerful method for the investigation of the physical reality; the error is turning it into ontology, i.e., claiming that only what is explainable with the adopted method is "real". The mysterious aspect of identity - an essential aspect of social life, formally held by documents like passports, identity cards and VAT identification numbers - is the fact of remaining the same despite unceasingly transforming oneself over time. It is a process involving both mind and body, including the molecular components of its anatomic structure: a sort of conundrum, where identity is kept despite a total transformation over time. What remains the same does not seem to be easily explainable based on a materialistic analysis alone, while the subjective dimension is no less real than the objective one in the dynamic relation mind-body-outer world - the knowledge of the latter closely depending on the former.

The very concept of identity is variable, ranging from the firm mathematical identity and Aristotle's principles of identity to something with a much lower level of identity, such as exact similarity or Klein's sameness (2014). Aristotle's logic is self-contradictory over time, since any phenomenon changes and is doomed to disappear (Severino, 2016); on the other hand, the concept of sameness implies an assessment of how much an entity remains the same despite its changes. The problem had already been posed in ancient Greece with the paradox of Theseus' ship, preserved by replacing the rotten planks until no original planks were left. At the end, was the mythical ship still the same? If not, when, during maintenance, did the ship cease to be the same? When men are concerned, this quantitative approach to identity does not seem to work.

According to Klein (2014), "the continual change associated with the psycho-physical existence would make personal diachronicity (i.e., the sameness of the person over time) a logical impossibility (unless one subscribed to a view in which change is an illusion, and the reality behind the illusion is in a state of stasis)". Here, the empiricist approach relying on memory is weak and provides contradictory results affected by a vicious circularity (i.e., memory cannot demonstrate identity, since it presupposes the diachronic sameness of Self). One should also consider the identity in physiological conditions, such as sleep or extreme disorders of consciousness like comas, be it reversible or irreversible: if one admits that identity is preserved, even in these conditions (as it is socially held), 
then the core of identity might lay in the background as a steady, unconscious component of the mindbody unit ${ }^{9}$.

Western scientific knowledge of the Self has been based on its attributes and functions - e.g., Selfawareness, Self-knowledge... Self-anything else - rather than its nature, in a culture that has overemphasized consciousness and Ego, understated the unconscious and adopted a ruling objectivistic stance. As a result, the nature of the Self, which remains a matter of subjective experience, has been poorly investigated and understood, being hardly compatible with the adopted scientific method. According to Eastern philosophies, the true Self is pure awareness, void of any mental object and attachment: it is a sort of internal witness not unsettled by events, that lays undisturbed in the depths of the mind as one's identity. If this is the case, enlarging the Self to encompass the internal witness through meditation allows for the development of full awareness and samāahi, as well as the highest form of resilience. Likewise, Plato, in Phaedo, discussed the nature of Self (here also called soul) as partaking in the ideal and invisible, warning against the error of confusing the external circumstances of man with his higher Self, which is not to be sought in the things of the world. He also faced the problem of identity as follows: “... Are they all unchanging and the same always, or quite the reverse? May they not rather be described as almost always changing and hardly ever the same, either with themselves or with one another? ... And these you can touch and see and perceive with the senses, but the unchanging things you can only perceive with the mind--they are invisible and are not seen? ... And were we not saying long ago that the soul when using the body as an instrument of perception... is then dragged by the body into the region of the changeable, and wanders and is confused; the world spins round her, and she is like a drunkard, when she touches change?... But when returning into herself she reflects... then she ceases from her erring ways, and being in communion with the unchanging is unchanging. And this state of the soul is called wisdom?".

In short, the problem of Self and its diachronic identity is a matter of an irreducible subjectivity, while its dimension cannot be constrained within the limits of the ruling materialist monist view of neurosciences with its 3PP: what is questionable is not its 3PP, but only the claim of its exclusivity.

\footnotetext{
${ }^{9}$ Interestingly, Buddhist ālayavijñāna (the primordial base of consciousness or consciousness-depository) is unconscious, is already present in the fetus and persists in coma.
} 


\section{Conclusions}

Both science and philosophy have investigated the Self and a wealth of valuable information are available; however, its definition remains elusive. From the above discussion, one can draw a number of key points which may provide some helpful clues in the process of comprehending the nature of Self:

1. The problem of Self is thoroughly interdisciplinary, involving both scientific and humanistic disciplines, and is endowed with profound epistemological and metaphysical implications.

2. The hard job of defining the Self has been affected by huge semantic problems and the related risk of misunderstandings, leading to ostensibly contradictory statements. When the Self is equated to the Ego, both the spiritual Self and puruṣa (pure consciousness) can be only described in terms of no-Self, but Self and smriti (mental presence) play a key role in Buddhism, like the concept of niroḍa in Yoga (implying a full mind control). Thus, a proper approach calls for recognizing all sources of misunderstanding stemming from language, prejudices, cultural filters and logic tricks; it is also made harder by the fact that the nature of Self seems to slip away from any conceptual restraint.

3. The concepts of self-awareness and self-knowledge look to be only partial features of the Self; furthermore, each of them have a wide range of levels, from Narcissus' simple selfrecognition, to metacognition and the highest forms of awareness, including the Russel's concept of enlarged Self, wisdom and enlightenment. This may introduce a further source of ambiguity and misunderstanding, if not taken into account.

4. A scientific reductionist approach remains essential for the explanation of brain machinery related to the material, objectifiable features of the Self, but is blind to the Self in its subjective dimension. Despite not being objectifiable, this aspect remains of paramount importance and rests concealed in the background of the different Self activities as a sort of strange attractor or an internal witness: the inescapable core of the individual, which has been well perceived and managed by Eastern philosophies.

5. Denying the value of subjectivity looks to be self-contradictory and self-destructive, since the whole culture - including science itself - are a product of the human mind with its irreducibly subjective nature and live in the world of consciousness. As a result, the study of subjective phenomena, including the Self, call for a neurophenomenological approach merging both the $1 \mathrm{PP}$ and $3 \mathrm{PP}$.

6. Introspective techniques like meditation and hypnosis have increasingly demonstrated their power to modulate mind-brain activity by top-down regulation, as well as their metacognitive 
and therapeutic potential. After all, meditation has been successfully used for no less than three millennia in Eastern cultures as a way to master liberation from suffering, develop metacognition and resilience and allow for the full realization of the Self. In this regard, it is worth noting that Western science discovered the unconscious some 2500 years later than Eastern philosophies and has only recently started to understand the value of meditation, thanks to the availability of sophisticated and expensive investigative techniques, such as fMRI. On the other hand, Eastern disciplines, like Yoga, developed and mastered it without spending a dollar, thanks to honed introspective activity. If this is the case, Eastern philosophies, including their introspective techniques and substantial knowledge, cannot be ignored any longer.

7. The hypothesis of a continuum Ego-I-Self is only a provisional, sketched figure merging them in a whole and calling for further examination. In fact, all of them look to reflect different developmental stages of the sense of individuality emerging from the relationship with the outer world. This continuum appears and is embedded in the in the social-historical dimension in its incessant transformation, where the Self itself is submitted to the same process of transformation as the rest of the world. The same is for the Ego (the primary component appearing in infancy, according to the psychanalytic concept of primary narcissism) and its evolution towards the I (the principle of reality, according to Freud). The Self includes both the Ego and I and transcends them; following its full development, it can reach the "consistency" advocated by Kant and become "strong" and "victorious on himself" according to Lăožr. This leads to the Ego-I narrower perspective being overcome and the whole sphere of the unconscious being encompassed and integrated - according to Jung's individuation or even buddhadhätu. If this hypothesis is acceptable, it can help better defining them as different stages of a functional aggregate, pole or attractor, taking into account their continuity. It can also help better defining them and reducing the interchangeability of their meanings: in fact, the Ego might be preferably used when emphasizing the narrow egocentric perspective, the I when dealing with a more objective relationship with reality, and the Self when metacognition, wisdom and the higher-order functions discussed above are considered. 


\section{References}

Adler, A. (1912). Il temperamento nervoso. Roma, Italy: Astrolabio (1950).

Adorno, F., Gregory, T., \& Verra, V. (2004). Manuale di storia della filosofia. Bari: Edizioni La Terza.

Arieti, S. (1967). The intrapsychic self: Feeling, cognition, and creativity in health and mental illness. New York, NY: Basic Books.

Armstrong, D. M. (2012). Sketch for a Systematic Metaphysics. Oxford, UK: Oxford University press Inc.

Assagioli, R. (1988). Transpersonal Development. (2007th ed.). Forres, Scotland: Smilin Wisdom, imprint of Inner Way Productions.

Bartha, P. (2016). Analogy and Analogical Reasoning. In Stanford Encyclopedia of Philosophy (pp. 1-69). Stanford, CA: The Metaphysics Research Lab Center for the Study of Language and Information Stanford University.

Benedetti, F., Lanotte, M., Lopiano, L., \& Colloca, L. (2007). When words are painful: unraveling the mechanisms of the nocebo effect. Neuroscience, 147(0306-4522 (Print)), 260-271.

Bettelheim, B. (1972). The Empty Fortress: Infantile Autism and the Birth of the Self. New York: Free Press.

Bryant, E. (2009). The Yoga Sutras of Pataljali. New York: North Point Press.

Buckner, R. L., Andrews-Hanna, J. R., \& Schacter, D. L. (2008). The brain's default network: anatomy, function, and relevance to disease. Annals of New York Academy of Sciences, 1124(0077-8923 (Print)), 1-38.

Bunge, M. (2007). Blushing and the philosophy of mind. Journal of Physiology, Paris, 101(09284257 (Print)), 247-256.Cardena, E., \& Facco, E. (2015). Non-Ordinary Mental Expressions. Front. Hum. Neurosci.

Buddharakkhita, A. (Ed.). (1985). Dhammapada. Sri Lanka: Buddhist Publication Society Kandy.

Burik, S. (2009). The End of Comparative Philosophy and the Task of Comparative Thinking:

Heidegger, Derrida, and Daoism. Albany: State University of New York Press.

Cameron, W. B. (1967). Informal Sociology, a casual introduction to sociological thinking. New York: Random House.

Cardeña, E. (2016). Toward comprehensive neurophenomenological research in hypnosis and meditation. In A. Raz \& M. Lifshitz (Eds.), Hypnosis and Meditation. Towards an Integrative Science of Consious Planes. (pp. 281-300). New York: Oxford University Press.

Cardena, E., Jonsson, P., Terhune, D. B., \& Marcusson-Clavertz, D. (2013). The 
neurophenomenology of neutral hypnosis. Cortex, 49(1973-8102 (Electronic)), 375-385.

Casiglia, E., Finatti, F., Tichonoff, V., Stabile, M. R., Mitolo, M., Albertini, F., ... Venneri, A. (in press). Mechanisms of hypnotic analgesia explained by functional magnetic resonance imaging. Brain Imaging and Behavior.

Casiglia, E., Tikhonoff, V., Giordano, N., Andreatta, E., Regaldo, G., Tosello, M. T., ... Facco, E. (2012). Measured outcomes with hypnosis as an experimental tool in a cardiovascular physiology laboratory. Int.J.Clin.Exp.Hypn., 60(1744-5183 (Electronic)), 241-261.

Chalmers, D. J. (1998). The problems of consciousness. Adv.Neurol., 77(0091-3952 (Print)), 7-16.

Chalmers, D. J. (2013). How can we construct a science of consciousness? Ann.N.Y.Acad.Sci., 1303(1749-6632 (Electronic)), 25-35.

Chambless, D. L., \& Goldstein, A. J. (1979). Behavioral Psychotherapy. In R. J. Corsini (Ed.), Current Psychotherapies. (2nd ed., pp. 230-272). Itasca, IL: Peacock Publishers.

Chen, Z., Qi, W., Hood Jr, R. W., \& Watson, P. J. (2011). Core Thesis and Qualitative and Quantitative Analysis of Mysticism in Chinese Buddhist Monks and Nuns. Journal for the Scientific Study of Religion, 50, 654-670.

Churchland, P. S. (2003). Self-representation in nervous systems. Ann.N.Y.Acad.Sci., 1001(00778923 (Print)), 31-38.

Cornu, P. (2001). Dictionnaire Encyclopédique du Buddhisme. Paris: Éditions du Seuil

Crabbe, J. (1999). From Soul to Self. New York, NY: Routledge.

Damasio, A. (1994). Descartes' error. New York: G.P. Putnam.

Damasio, A. (2003). Feelings of emotion and the self. Ann.N.Y.Acad.Sci., 1001(0077-8923 (Print)), 253-261.

Dosch, M., Loenneker, T., Bucher, K., Martin, E., \& Klaver, P. (2010). Learning to appreciate others: neural development of cognitive perspective taking. Neuroimage., 50(1095-9572 (Electronic)), 837-846.

Eliade, M. (1994). Techniques Du Yoga. Paris, France: Gallimard Education.

Facco, E., Pasquali, S., Zanette, G., \& Casiglia, E. (2013). Hypnosis as sole anaesthesia for skin tumour removal in a patient with multiple chemical sensitivity. Anaesthesia, 68(9), 961-965. https://doi.org/10.1111/anae.12251

Facco, E. (2014). Meditazione e Ipnosi tra neuroscienze, filosofia e pregiudizio. Lungavilla, PV, Italy: Altravista.

Facco, E. (2016). Hypnosis and anesthesia: Back to the future. Minerva Anestesiologica, 82(12), 1343-1356. 
Facco, E. (2017). Meditation and Hypnosis: Two Sides of the Same Coin? International Journal of Clinical and Experimental Hypnosis, 65(2), 169-188. https://doi.org/10.1080/00207144.2017.1276361

Facco, E. (2018). Ipnosi ed Esperienze di Premorte nel continuum delle Espressioni Non Ordinarie della Mente. Ipnosi, 1, 13-38.

Facco, E., Agrillo, C., \& Greyson, B. (2015). Epistemological implications of near-death experiences and other non-ordinary mental expressions: Moving beyond the concept of altered state of consciousness. Medical Hypotheses, 85(1), 85-93. https://doi.org/10.1016/j.mehy.2015.04.004

Facco, E., Casiglia, E., Masiero, S., Tikhonoff, V., Giacomello, M., \& Zanette, G. (2011). Effects of hypnotic focused analgesia on dental pain threshold. International Journal of Clinical and Experimental Hypnosis, 59(4 ), 454-468. https://doi.org/10.1080/00207144.2011.594749

Facco, E., Casiglia, E., Zanette, G., \& Testoni, I. (2017). On the way of liberation from suffering and pain: Role of hypnosis in palliative care. Annals of Palliative Medicine, 7(1), 2224-5839 (Electronic), 1-12. https://doi.org/10.21037/apm.2017.04.07

Facco, E. (2010). Esperienze di premorte. Scienza e coscienza ai confini tra fisica e metafisica. Lungavilla (PV): Edizioni Altravista.

Facco, E., \& Fracas, F. (2018). L'enigma della coscienza. Milano: Mondadori.

Facco, E., \& Zanette, G. (2017). The odyssey of dental anxiety: From prehistory to the present. A narrative review. Frontiers in Psychology, 8(JUL), 1855, 1-15. https://doi.org/10.3389/fpsyg.2017.01155

Facco, E., Lucangeli, D., \& Tressoldi, P. (2017). On the Science of Consciousness: Epistemological Reflections and Clinical Implications. EXPLORE: The Journal of Science and Healing, 13(3), 163-180. https://doi.org/10.1016/j.explore.2017.02.007

Facco, E., Lucangeli, D., \& Tressoldi, P. (2018). Dr. A.M. - A rare case of a modern Mystic? Implications for Psychology and Medicine. Spirituality in Clinical Practice, 1-22. http://dx.doi.org/10.1037/scp000017

Facco, E., Manani, G., \& Zanette, G. (2013). The relevance of hypnosis and behavioural techniques in dentistry. Contemporary Hypnosis and Integrative Therapy, 29(4), 332-351.

Facco, E., Pasquali, S., Zanette, G., \& Casiglia, E. (2013). Hypnosis as sole anaesthesia for skin tumour removal in a patient with multiple chemical sensitivity. Anaesthesia, 68(9), 961-965. https://doi.org/10.1111/anae.12251

Facco, E., Casiglia, E., Al Khafaji, B. E., Finatti, F., Duma, G., Mento, G., Pederzoli, L., \& 
Tressoldi, P. (in press). International Journal of Clinical and Experimental Hypnosis.

Ferrari, M. (2010). Introduction. Hist Human Sci., 23(0952-6951 (Print)), 1-14.

Forman, R. C. K. (1998). What does mysticism have to teach us about consciousness? Journal of Consciousness Studies, 5(2), 185-201.

Freud, S. (1923). The Ego and the Id (1990th ed.). New York, NY: W.W. Norton \& Comapny. Fromm, E. (1976). To Have or to Be? New York: Harper \& Row Publishers.

Fumerton, R. (2005). Speckled Hens and Objects of Acquaintance. Philosophical Perspectives, 19, $121-138$.

Gertler, B. (2017). Self-Knowledge. In The STanford Encyclopedia of Philosophy (pp. 1-67).

Huxley, A. (1946). The perennial philosophy. London: Chatto and Windus

Horney, K. (1991). Neurosis and Human Growth: The Struggle Towards Self-Realization. New York, NY: W. W. Norton \& Company.

Hume, D. (1739). A Treatise of Human Nature. London, UK: Penguin Classics (1985).

Huxley, A. (1954). The Doors of Perception and Heaven and Hell . New York, NY: Harper\& Brothers.

IASP Subcommittee on Taxonomy. (1979). Pain terms: a list with definitions and notes on usage.Pain, 6(3), 249.

Ionta, S., Heydrich, L., Lenggenhager, B., Mouthon, M., Fornari, E., Chapuis, D., ... Blanke, O. (2011). Multisensory Mechanisms in Temporo-Parietal Cortex Support Self-Location and First-Person Perspective. Neuron, 70(2), 363-374. https://doi.org/10.1016/j.neuron.2011.03.009

Izutsu, T. (1984). Sufism and Taoism: a comparative study of key philosophical concepts. Oakland, CA: University of California press.

James, W. (1882). The Subjective Effects of Nitrous Oxyde. Mind, 7. https://ebooks.adelaide.edu.au/j/james/william/nitrous/

James, W. (1890). Principles of Psychology. New York: Holt.

James, W. (1909). A Pluralistic Universe. Retrieved March 30, 2018, from https://jennymackness.files.wordpress.com/2016/08/james-william-a-pluralistic-universe.pdf James, W. (1917). The Varieties of Religious Experience. New York: Mentor Books, 1958. Jullien, F. (2015). De l'Etre au Vivre. Lexique eurochinoise de la pensée. Paris, France: Gallimard. Kant, E. (1781). Critique of Pure Reason. Cambridge, UK: CAmbridge University Press (1998). Kant, I. (1784). Answering the Question: What Is Enlightenment? Berlinische Monatsschrift. Dezember-Heft 1784, S. 481-494 
Kant, I. (1788). Critique of Practical Reason. Cambridge , UK: Cambridge Text in the History of Philosophy, 2015.

Kernberg, O. F. (1995). Borderline Conditions and Pathological Narcissism. New York, NY: Jason Aronson, Inc.

Kingsley, P. (1999). In the dark places of wisdom. Poin Reyes, California: The Golden Sufi Center. Kitarò, N. (2014). Problemi fondamentali della filosofia. Conferenze per la Società filosofica di Shinano. Venice, Italy: Marsilio Editori.

Klein, S. B. (2014). The Two Selves: Their Metaphysical Commitments and Functional independence. Oxford, UK: Oxford University Press.

Klinger, R., \& Colloca, L. (2014). Placebo effects: Basic mechanisms and clinical applications. Z.Psychol, 222(2190-8370 (Print)), 121-123.

Kohut, H. (1977). The Restoration of the Self. Chicago, USA: University of Chicago Press.

Kong, J., Gollub, R. L., Rosman, I. S., Webb, J. M., Vangel, M. G., Kirsch, I., \& Kaptchuk, T. J. (2006). Brain activity associated with expectancy-enhanced placebo analgesia as measured by functional magnetic resonance imaging. J.Neurosci., 26(1529-2401 (Electronic)), 381-388.

Lazerowitz, M. (1970). A note on metaphylosophy. Metaphilosophy, 1(1), 91.

Lao Tzu. (2009). Tao Te Ching. London, UK: Penguin Books Ltd.

Locke, J. (1689). An Essay Concerning Human Understanding. London: Penguin Books (1997).

MacBride, F. (2016). Truthmakers. In Stanford Encyclopedia of Philosophy (pp. 1-68). https://plato.stanford.edu/entries/truthmakers/

MacLean, K. A., Johnson, M. W., \& Griffiths, R. R. (2011). Mystical experiences occasioned by the hallucinogen psilocybin lead to increases in the personality domain of openness. Journal of Psychopharmacology, 25(11), 1453-1461. https://doi.org/10.1177/0269881111420188

Maslow, A. H. (1954). Motivation and Personality. New York, NY: Harper and Row.

May, R. (1978). Psychology and the Human Dilemma. New York, NY: W. W. Norton \& Company.

Mead, G. (1934). Mind, Self \& Society. Chicago, USA: University of Chicago Press.

Merskey, H. (1994). Logic, truth and language in concepts of pain. Qual.Life Res., 3 Suppl 1(09629343 (Print)), S69-S76.

Merskey, H. (2007). The taxonomy of pain. Med.Clin.North Am., 91(0025-7125 (Print)), 13-20, vii.

Minsky, M. (1986). The Society of Mind. New York, NY: Simon \& Schuster.

Moreira-Almeida, A., Sharma, A., van Rensburg, B. J., Verhagen, P. J., \& Cook, C. C. (2016). 
WPA Position Statement on Spirituality and Religion in Psychiatry. World Psychiatry, 15(1723-8617 (Print)), 87-88.

Morin, A. (2017). Toward a Glossary of Self-related Terms. Frontiers in Psychology, 8, 280. https://doi.org/10.3389/fpsyg.2017.00280

Neisser, U. (1988). Five kinds of self-knowledge. Philosophical Psychology, 1(1), 35-59. https://doi.org/10.1080/09515088808572924

Nichols, D. (1999). Psychedelic Research Demystified. From Eleusis to PET scans: the mysteries of psychedelics. MAPS, 9(50-55).

Nida-Rumelin, M. (2015). Qualia: The Knowledge Argument. In E. N. Zalta (Ed.), Stanford Encyclopedia of Philosophy (pp. 1-38). http://plato.stanford.edu/archives/sum2015/entries/qualia-knowledge/

Orme-Johnson, D. W., Schneider, R. H., Son, Y. D., Nidich, S., \& Cho, Z. H. (2006). Neuroimaging of meditation's effect on brain reactivity to pain. Neuroreport, 17(0959-4965 (Print)), 1359-1363.

Oursel, P. M. (1923). La philosopie comparée. Paris, France: Alcan.

Overgaard, S., Gilbert, P., \& Burwood, S. (2013). Introduction: what good is metaphilosophy? In An Introduction to Metaphilosophy. (pp. 1-10). Cambridge , UK: Cambridge University Press. https://doi.org/https://doi.org/10.1017/CBO9781139018043

Pasqualotto, G. (2008). East \& West. Venice, Italy: Marsilio Editori.

Patanjali Yoga-Sutra. (2009). Abano Terme: Union Trust.

Pockett, S. (2014). Problems with theories that equate consciousness with information or information processing. Frontiers in System Neuroscience, 8(1662-5137 (Electronic)), 225.

Priest, G. (1990). True contradictions. Can.J.Philosophy, 20(335), 353.

Priest, G. (1998). What is so bad about contradictions? J.Philosophy, 95(8), 410-426.

Ramsay, W. (2013). ELiminative materialism. In E. Zalta (Ed.), The Stanford Encyclopedia of Philosophy (pp. 1-16).

https://plato.stanford.edu/archives/win2016/entries/materialism-eliminative/

Rogers, C. R. (1951). Client-Centered Therapy: Its Current Practice, Implications and Theory. London, UK: Constable.

Ruby, P., \& Decety, J. (2004). How would you feel versus how do you think she would feel? A neuroimaging study of perspective-taking with social emotions. J.Cogn Neurosci., 16(0898929X (Print)), 988-999.

Russel, B. (1912). Problems of Philosophy. Oxford, UK: Oxford University Press. 
Russell B. (1959).Wisdom of the West. London: Rathbone Books Ltd.

Salomon R, Lim M, Pfeiffer C, Gassert R, Blanke O. (2013) Full body illusion is associated with widespread skin temperature reduction. Fronters of Behavioral Neurosciences , 7, 65.

Samorini, G. (2000). A contribuition to the discussion on the ethnobotany of the Eleusinian Mysteries., 4, 3-53.

Scarpi, P. (2012). Le religioni dei misteri. (Vol. I). Milano: Mondadori.

Severino, E. (2016). The Essence of Nihilism. Brooklin, NY: Verso.

Smith, R. (2018). Aristotle's Logic. In E. N. Zalta (Ed.), Stanford Encyclopedia of Philosophy (pp. 1-55). Stanford, CA.

Sturm, T., \& Wunderlich, F. (2010). Kant and the scientific study of consciousness. History of the Human Sciences, 23(3), 48-71.

Sullivan, H. S. (1955). The Interpersonal Theory of Psychiatry. London, UK: Tavistock Publications Ltd.

Suzuki T., D. (1958). The Zen doctrine of no-mind. London: Rider \& Co.

Swami Veda Bharati. (2009). Yoga Sutras of Patanjali. New Delhi, India: MLBD.

Tressoldi, P., Facco, E., \& Lucangeli, D. (2017). On the primacy and irreducible nature of firstperson versus third-person information. FR1000Research, 6(99), 1-32. https://doi.org/10.12688/f1000research.10752.3

Tye, M. (2018). Qualia. In E. N. Zalta (Ed.), Stanford Encyclopedia of Philosophy (pp. 1-39). https://plato.stanford.edu/archives/sum2018/entries/qualia/

Varela, F. J. (1996). Neurophenomenology: a methodological remedy to the hard problem. Journal of Consciousness Studies, 3, 330-350.

Vogeley, K., \& Fink, G. R. (2003). Neural correlates of the first-person-perspective. Trends Cogn Sci., 7(1879-307X (Electronic)), 38-42.

Vogeley, K., May, M., Ritzl, A., Falkai, P., Zilles, K., \& Fink, G. R. (2004). Neural correlates of first-person perspective as one constituent of human self-consciousness. J.Cogn Neurosci., 16(0898-929X (Print)), 817-827.

Weber, R. (2013). "How to Compare?” - On the Methodological State of Comparative Philosophy. Philosophy Compass 8/7: 593-603. https://doi.org/10.1111/phc3.12042

Wilczek. (2010). The Lightness of Being. Mass, Ether, and the Unification of Forces. (B. Books, Ed.). New York, NY.

Wilhelm, H. (Ed.). (1950). The I Ching (3rd ed.). Princetown, USA: Princeton University, 1997 
Press.Zajonc A. (2004). The New Physics and Cosmology. Dialogues with the Dalai Lama. New York: Oxford University Press.

Zadeh, L. A. (1965). Fuzzy Sets. Information and Control, 8, 338-353.

Zeidan, F., Martucci, K. T., Kraft, R. A., Gordon, N. S., McHaffie, J. G., \& Coghill, R. C. (2011). Brain mechanisms supporting the modulation of pain by mindfulness meditation. Journal of Neuroscience, 31(1529-2401 (Electronic)), 5540-5548.

Zeman, A. (2001). Consciousness. Brain, 124(0006-8950), 1263-1289.

Zeman, A. (2006). What do we mean by "conscious" and "aware"? Neuropsychology and Rehabilitation, 16(0960-2011 (Print)), 356-376.

Zeman, A. (2009). The problem of unreportable awareness. Progress in Brain Research, 177(18757855 (Electronic)), 1-9.

Zhuangzi. (2009). Zhuangzi. Indianapolis, US: Hackett Classics. 